Annuaire suisse de politique de développement

22-2 | 2003

Société de l'information et coopération internationale

\title{
ETIC : partenariat Nord-Sud et coopération décentralisée
}

Pape Ndiaye Diouf

\section{(2) OpenEdition}

1 Journals

Édition électronique

URL : http://journals.openedition.org/aspd/573

DOI : $10.4000 /$ aspd. 573

ISSN : 1663-9669

Éditeur

Institut de hautes études internationales et du développement

Édition imprimée

Date de publication : 1 novembre 2003

Pagination : 149-150

ISSN : 1660-5934

\section{Référence électronique}

Pape Ndiaye Diouf, «ETIC : partenariat Nord-Sud et coopération décentralisée », Annuaire suisse de politique de développement [En ligne], 22-2 | 2003, mis en ligne le 22 mars 2010, consulté le 08 septembre 2020. URL : http://journals.openedition.org/aspd/573; DOI : https://doi.org/10.4000/aspd. 573 


\title{
ETIC: partenariat Nord-Sud et coopération décentralisée
}

\author{
Pape Ndiaye Diouf*
}

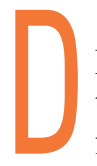

'où vient le projet ETIC Espaces Technologies Information Communication ? ${ }^{1}$ Il se fonde sur une analyse critique et constructive de l'évolution de quelques pays ouest-africains en matière de technologies de l'information et de la communication (TIC), à partir de deux sources: d'abord, les travaux menés sur le terrain entre 1998 et 2001 par une équipe du Centre national de la recherche scientifique (CNRS) de Bordeaux et de l'Institut universitaire d'études du développement (iuéd), au Sénégal, au Mali, en Guinée, en Côte d'Ivoire et au Ghana; ensuite, le travail considérable accompli ces vingt dernières années par les radios communautaires et rurales - surtout en Afrique de l'Ouest - qui, en donnant la parole aux paysans, pêcheurs et autres artisans, leur a permis de mieux défendre leurs intérêts et de renforcer leur pouvoir.

Ces études ont notamment permis :

$\square$ un travail de démystification. Si les TIC se développent rapidement en Afrique, leur arrivée massive ne suffit pas à produire des effets positifs et durables sur les conditions de vie du plus grand nombre. De fait, comme l'expérience le montre, la seule présence d'une technologie n'a jamais garanti le progrès d'une société. Par ailleurs, le risque est grand que ces TIC ne soient accaparées par les seules élites et une minorité de privilégiés. Pourtant, nombre de gens et d'institutions en Afrique continuent à penser et agir comme si elles étaient automatiquement porteuses de développement, s'inscrivant presque «naturellement» dans le processus de modernisation des sociétés en place;

$\square$ l'identification d'un certain nombre de besoins et de demandes exprimés par différentes catégories d'acteurs - élus locaux, agents de l'administration, entrepreneurs, groupements de producteurs et associations de jeunes et de femmes - impliqués dans le développement de leurs zones ou pays.

Le but de l'association ETIC NordSud, créée en 2001 à Genève à l'initiative d'Africains et de Suisses, est précisément de répondre à ces besoins par une approche novatrice et partenariale des TIC. Une approche fondée sur un modèle de coopération décentralisée susceptible d'offrir une contribution significative au développement durable et à l'amélioration effective des conditions de vie du plus grand nombre, et de soutenir les

\footnotetext{
Chargé de cours à l'Institut universitaire d'études du développement (iuéd), Suisse.

$<$ www.etic-nordsud.org $>$.
} 
pays africains dans leurs efforts pour relever certains défis sociaux, économiques, culturels et politiques.

Cela suppose, contrairement à ce qui se passe trop souvent, de mettre l'accent sur la dimension humaine et sociale des TIC plutôt que sur leurs aspects techniques, malheureusement dominants aussi bien dans le processus de préparation du Sommet mondial sur la société de l'information que dans le cadre du NEPAD (Nouveau Partenariat pour le développement de l'Afrique).

Dans cette perspective, plus concrètement, deux points sont prioritaires pour ETIC :

$\square$ développer les ressources humaines et les compétences à travers des prestations de vulgarisation, d'initiation et de formation. Une manière de mettre les ressources techniques à la disposition et au profit des sociétés locales, notamment dans les zones urbaines défavorisées et en milieu rural. Sans de tels efforts de formation et de maîtrise des TIC sur le plan des communautés de base, une appropriation réussie des TIC en Afrique ne sera pas possible;

$\square$ favoriser l'accès du plus grand nombre à des équipements et services de qualité en matière de TIC.

Les publics cibles couvrent différentes catégories d'acteurs dans les secteurs suivants : écoles primaires et secondaires, groupements de jeunes, femmes et producteurs, agents de l'administration communale, personnel de santé.

Pour réaliser ces objectifs, l'association ETIC va mettre sur pied un réseau d' «espaces» décentralisés, dotés des ressources nécessaires, tant en termes d'accès que de capacités de formation - ce que nous appelons précisément des etics. Ces espaces ont pour vocation d'être des lieux où se réalisent tout à la fois :

$\square$ un meilleur partage du pouvoir et des ressources;

$\square$ une solidarité nationale et internationale accrue et mieux maîtrisée par l'établissement de relations plus directes et «raccourcies» (en temps et en distance) entre tous les acteurs concernés, au Sud et au Nord, à la base comme dans les administrations et les agences de coopération;

$\square$ une intensification des échanges d'expériences, d'informations et d'idées entre ces mêmes acteurs;

$\checkmark$ un renforcement des capacités des communautés de base et des collectivités locales à négocier et répondre aux besoins des gens;

$\square$ une plus grande transparence dans la gestion des programmes de développement, grâce à un suivi, un contrôle et une évaluation plus réguliers, plus systématiques et plus efficaces.

Pour réaliser ce projet, l'association est elle-même organisée sur le double principe de la coopération décentralisée en Afrique et du partenariat entre la Suisse et l'Afrique. Elle œuvre sur le terrain en s'appuyant sur des comités nationaux ETIC - celui du Sénégal, qui abrite la phase pilote, a été créé en 2002 - reliés au Comité de l'association à Genève. Chacun de ces comités nationaux doit susciter à son tour la création de comités locaux composés de représentants des forces sociales existantes dans les localités et les quartiers où se déroulent ses activités. 